\title{
Characterization of Dumpsite Leachate: Case Study of Ogbomosoland, South-Western Nigeria
}

\author{
Samson O. Ojoawo ${ }^{1 *}$, Oluwole A. Agbede ${ }^{2}$, Abimbola Y. Sangodoyin ${ }^{3}$ \\ ${ }^{1}$ Department of Civil Engineering, Ladoke Akintola University of Technology, Ogbomoso, Nigeria \\ ${ }^{2}$ Department of Civil Engineering, University of Ibadan, Ibadan, Nigeria \\ ${ }^{3}$ Department of Agricultural and Environmental Engineering, University of Ibadan, Ibadan, Nigeria \\ Email: "soojoawo@lautech.edu.ng, oluwoleagbede@yahoo.com,bimbo_sangodoyin@yahoo.co.uk
}

Received September 3, 2011; revised October 24, 2011; accepted November 4, 2011

\begin{abstract}
Leachates contain varying complex characteristics. The 5 Local Government Areas (LGAs) under this study that characterized leachate are no exceptions. Five aged dumpsites, one per LGA were selected and leachates extracted from them through BS 1377 standard method. Samples were taken seasonally over 2 years and subjected to Laboratory analyses for physical, inorganic, metallic and microbial characteristics. The key leachate contents mean, (pollution indices) included Nickel (0.2 mg/l), Manganese (1.8 mg/l), Dissolved Oxygen (11.5 mg/l) and Total Coliform (24.3 $\mathrm{cfu} / \mathrm{ml}$ ). Results obtained were compared with the Nigerian Federal Environmental Protection Agency (FEPA) standards. The leachate of the area is found to be stable, objectionably coloured, odoured, alkaline, turbid, hard, with moderate recalcitrant organic and biological matters. The study recommends leachate treatment to minimize groundwater pollution.
\end{abstract}

Keywords: Leachate; Dumpsites; Ogbomosoland; Nigeria

\section{Introduction}

Leachate is that liquid formed when water passes through the waste in a dumpsite [1].

Landfill leachate is a complex cocktail of chemicals and it can have a detrimental effect on groundwater quality. Calvert [2] had the earliest organized publication on leachate from domestic landfill sites. In his report, the contamination of groundwater was due to leachate migration from refuse slurry 500 meters away from groundwater wells. The quality of leachate is controlled primarily by the specific water flux into the landfill system, which is, in turn, determined by the amount of precipitation. Leachates have stronger characteristics than sewage. According to [3], a typical young leachate may have a chemical oxygen demand (COD) 36 times higher than raw sewage, whereas a mature leachate may be equal in COD to raw sewage but containing much more recalcitrant organic constituents than domestic sewage. The composition of municipal landfill leachate exhibits noticeable temporal and site-specific variation. This variation in chemical and microbiological characteristics is attributed to a combination of factors including landfill age, waste nature, moisture availability, temperature, $\mathrm{pH}$, depth fills, and compaction $[4,5]$.

\footnotetext{
${ }^{*}$ Corresponding author.
}

The general trend between leachate composition and landfill age was demonstrated that leachate toxicity decreased somewhat with time [6]. On the other hand, [7] postulated that the stabilization rate of waste is dependent on the movement of water through the fill, which in turn is influenced by infiltration. Hence the leachate stabilization will not necessarily be related directly to chronological age. Natural leachates were highly toxic within the confines of landfills and usually remained so even at the point of receiving stream discharge, in spite of being attenuated somewhat by time because of considerable dilution afforded surface drainage and groundwater.

Temporal changes in toxicity paralleled the documented patterns of variation that characterized other leachate parameters i.e. an apparent logarithmic decay over time as the landfill ages [8]. The leachate components which dissolve into water percolating through the waste reach a solubility limit. Further release of these components can then only be achieved by the passage through the waste of additional less contaminated water [9]. According to [10], leachate constituents such as chlorides, for which the solubility is relatively unaffected by $\mathrm{pH}$, showed no clear shift in progressing from acidic leachate (characteristic of the anaerobic acetogenic phase) to the methane-producing phase. Constituents like metal ions, which are more soluble under acidic conditions, showed a clear 
decrease in concentration in progressing from acidic phase to methane-producing phase.

In related studies by same author, the measured COD revealed that at about 8 years, the COD at the sample stabilized to approximately $8000 \mathrm{mg} / \mathrm{l}$ due to the biological and mass transport systems in the landfill maturing. From the research by [11], it was discovered that the types, amounts and production rates of contaminants appearing in leachate at a landfill site are influenced by the type of refuse, the composition of refuse, refuse density, pre-treatment, placement sequence and the depth. In contrast to this, [12] postulated that the time taken for a landfill to reach so-called final storage quality will be many centuries in a moderate climate. It was also observed that in the landfill leachate, there was a general increase in metal ion content and this was related to an increase in the acidity of the leachate. Also there was a clear correlation between various metal concentrations in the study. Particular ones, which were significant, included correlation between lead/cadmium (63\%), copper/cadmium (77\%), copper/lead (64\%) and copper/chromium (64\%).

Due to the decomposition of organic matter, leachate derived from landfills or dumps comprises primarily dissolved organic carbon, largely in the form of fulvic acids [13]. The solubility of metals in leachate is enhanced when made complex by dissolved organic matter. The solubility of organic contaminants (e.g. solvents) in wastes may also be slightly enhanced through the presence of high level of organic carbon in the leachate.

The chemical composition of leachate changed over time [14]. A rapid consumption of volatile fatty acids results in the reduction of COD values. This resulted in simultaneous increase in $\mathrm{pH}$ values which in turn reduced the aggressive nature of the leachate. The leachate samples taken from unsaturated parts of the refuse also revealed that while the leachate quality at the refuse/liner interface demonstrated methanogenic qualities, in fact acetogenic conditions were still prevailing in the unsaturated zones of the refuse. However, a significant impact of landfill on soil quality is from the production of leachate, a liquid that may contain a wide range of pathogens and chemical pollutants [15].

International standards have thus specified that the minimum safe distance that a well and the contaminating source should be apart is 30meters. In an earlier work on Ibadan dumpsites, [16], it was discovered that the level of pollutants was in the following order: leachate > stream $>$ well. In a related research, [17], it was reported that sources of underground water pollution include leachate from refuse dumps, unlined surface sullage, animals an birds, and human activities. The characterization of leachate in a given region is therefore pertinent in safeguarding the underground water through the most suitable leachate control means.
The central aim of this paper is to characterize the leachates extracted from the dumpsites in Ogbomosoland, South-Western Nigeria. This would further assist in determining the level of environmental pollution emanating from these leachates. The 5 Local Government Areas in Ogbomosoland are Ogbomoso North and South (both in the city), Oriire, Ogo Oluwa and Suurulere (at the suburb).

\section{Methodology}

\subsection{Measured Characteristics}

Some major parameters of the leachate in Ogbomosoland were used to measure its characteristics. The parameters determined include physical ones such as appearance, odour, colour, temperature, turbidity, total solids and conductivity. Chemical/inorganic constituents tested were $\mathrm{pH}$, zinc, copper, lead, nickel, iron, sodium, potassium, calcium, total alkalinity, total hardness, chloride, phosphate, sulphate, sulphite, nitrate, magnesium, chromium, manganese, and cadmium. Organic contents include BOD5, COD and DO while Total Coliform was the only microbial parameter examined.

\subsection{Collection of Leachate Samples}

Five representative dumpsites were selected in each of the LGAs as shown on Table 1. The dumpsites cut across the various types of wastes in the study area, ranging from domestic to industrial, institutional, agricultural and residential. A seasonal quality monitoring exercise of the leachates emanating from these dumps was carried out over 2 years. The collection of samples covered both dry and wet seasons of the 2 years. Replica samples were taken in each season.

\subsection{Processing of Leachate Samples}

The standard leachate processing procedure ([18-20]) was followed. The step-wise procedure was:

1) Various decomposed waste samples were collected from pre-determined lowest points in each of the dunghills at soil depths $0.5 \mathrm{~m}, 1.0 \mathrm{~m}$, and $1.5 \mathrm{~m}$ respectively.

2) The collected samples were mixed into a single composite sample through thorough shaking.

3) Leaching was done by the continuous column leaching. The homogenized samples were put by gentle tapping into improvised plastic columns. The column was soaked with leaching solution (distilled-deionized water) and allowed to stay overnight. The column was then leached by gravity.

4) The column was maintained properly wet and leached again after 5 days. The topmost and lowest $1 \mathrm{~cm} \mathrm{-} 2$ $\mathrm{cm}$ end of the column material was removed and dried and leached by batch method through the leaching agent. 
Table 1. Classification of the dumpsites studied in Ogbomosoland.

\begin{tabular}{|c|c|c|c|c|}
\hline $\mathrm{S} / \mathrm{N}$ & Dumpsite Location & Age & Type of waste & LGA \\
\hline 1 & R.A. Bello street, stadium area & 18 & Residential & Ogbomoso North \\
\hline 2 & Attenda abattoir & 19 & Industrial (Animal products) & “ \\
\hline 3 & Owode area & 15 & Commercial & “ \\
\hline 4 & SUB area, LAUTECH & 10 & Institutional & “ \\
\hline 5 & Masifa area & 13 & Residential & “ \\
\hline 6 & Aarada market & 20 & Commercial (Agricultural products) & Ogbomoso South \\
\hline 7 & Laka river bank & 18 & Residential & “ \\
\hline 8 & High School area & 13 & Institutional & “ \\
\hline 9 & Odokoto area & 12 & Residential & “ \\
\hline 10 & Adeleke sawmill & 10 & Industrial (Wood products) & “ \\
\hline 11 & Olorombo dumpsite & 14 & Residential & Oriire \\
\hline 12 & L.A. primary school & 13 & Institutional & “ \\
\hline 13 & Behind Iluju market & 15 & Commercial & “ \\
\hline 14 & Adafila dumpsite & 11 & Agricultural & “ \\
\hline 15 & Ahoro Dada dumpsite & 12 & Residential & “ \\
\hline 16 & Ikolaba area dumpsite & 11 & Commercial (Agricultural products) & Ogo Oluwa \\
\hline 17 & Otamokun dumpsite & 15 & Residential & “ \\
\hline 18 & Behind Ajaawa Hotels & 12 & Residential & “ \\
\hline 19 & Iwo-Ate, behind Ile Baale & 10 & Residential & “ \\
\hline 20 & Lagbedu dumpsite & 14 & Agricultural & “ \\
\hline 21 & Behind central market, Iresa-Adu & 13 & Agricultural & Suurulere \\
\hline 22 & Dumpsite at Oko market area & 11 & Commercial & “ \\
\hline 23 & Behind Gambari motor park & 14 & Industrial (Automobile) & “ \\
\hline 24 & Behind primary school, Iresa-Apa & 14 & Institutional & “ \\
\hline 25 & Baaya Oje dumpsite & 12 & Agricultural & “ \\
\hline
\end{tabular}

5) The leachates were separated from the residues by filtration through filter papers.

6) The leachates so extracted were consequently analyzed for their characteristics.

\subsection{Laboratory Analysis of the Leachate Samples}

Each leachate sample obtained in the procedure above was analysed for its physico-chemical and microbial characteristics. The analysis is in accordance with the [21] standard.

\section{1) Analysis of physical parameters}

The main physical parameters analysed are the appearance, colour, odour, temperature, turbidity, conductivity and total dissolved solids. These were all measured in accordance with standard methods viz: [21] and [22].

\section{2) Analysis of inorganic constituents}

The methods used in obtaining results during the analysis of inorganic constituents' tests were both colorimetric and titrimetric. The former method is one in which the reagent and water samples were mixed until the solid dissolved. The solution was then poured into either comparator or checker disc depending on the specification of the manufacturer. The titration method on the other hand involved the addition of reagents to water sample until the colour changed at the end points.

\section{3) Analysis of metals}

In the analysis of metals, the technique of flame atomic absorption spectrophotometry [23] was adopted. The atomic absorption spectrophotometer (AAS) was used for the analysis of the following metals: zinc, copper, lead, nickel, iron, sodium, potassium, calcium, magnesium, chromium, manganese and cadmium.

\section{4) Microbial analysis}

According to [22], total coliform includes all grain, negative, non-spore forming rods capable of fermenting lactose with the production of acid and gas within 48 hours at $37^{\circ} \mathrm{C}$. They are therefore capable of growing aerobically on an agar medium containing bile salt. The determination of total coliform in the leachate samples was done in line with the standard method [24].

\section{Results and Discussion}

The mean results of the leachate characteristics monitored 
over four (4) seasons between the 2 years are presented in Tables 2 and 3.

\subsection{Comparative Analysis by LGA}

The total mean values of the leachate parameters measured in Ogbomosoland are presented in Table 2. The comparison of the characteristics of leachate in the study area with the FEPA standard is as shown in Table 3. From Tables 2 and 3, it is observed that 13 parameters have values exceeding the FEPA standard in Ogbomoso North LGA. The data indicate heavy levels of pollution except the total hardness. The leachate characteristics with pollution levels below the FEPA standard values are 12 in number. The heavy industrial activities in the city might be

Table 2. Leachate characteristics of Ogbomosoland.

\begin{tabular}{|c|c|c|c|c|c|}
\hline \multicolumn{6}{|c|}{ Mean values $\pm 2 \sigma$} \\
\hline Parameter & Ogbomoso North & Ogbomoso South & Oriire & Ogo Oluwa & Suurulere \\
\hline Appearance & Cloudy & Cloudy & Cloudy & Cloudy & Cloudy \\
\hline Colour & Objectionate & Objectionate & Objectionable & Objectionable & Objectionable \\
\hline Odour & Objectionate & Objectionate & Objectionable & Objectionable & Objectionable \\
\hline Temperature & $26.21 \pm 0.64$ & $28.91 \pm 0.09$ & $25.66 \pm 0.66$ & $25.76 \pm 0.68$ & $25.56 \pm 0.67$ \\
\hline Conductivity & $87.11 \pm 16.44$ & $113.49 \pm 7.69$ & $117.94 \pm 11.75$ & $58.40 \pm 2.07$ & $55.75 \pm 4.54$ \\
\hline Turbidity & $13.30 \pm 1.75$ & $5.10 \pm 0.40$ & $5.10 \pm 0.35$ & $5.45 \pm 0.32$ & $4.95 \pm 0.32$ \\
\hline $\mathrm{pH}$ & $8.19 \pm 0.11$ & $7.80 \pm 0.02$ & $7.77 \pm 0.02$ & $7.83 \pm 0.01$ & $7.79 \pm 0.04$ \\
\hline Zinc & $31.09 \pm 6.03$ & $10.78 \pm 0.50$ & $6.86 \pm 0.25$ & $10.23 \pm 0.49$ & $6.14 \pm 0.85$ \\
\hline Copper & $0.61 \pm 0.02$ & $0.55 \pm 0.11$ & $0.00 \pm 0.00$ & $0.05 \pm 0.01$ & $0.76 \pm 0.18$ \\
\hline Lead & $0.01 \pm 0.0009$ & $0.02 \pm 0.01$ & $0.01 \pm 0.00$ & $0.04 \pm 0.00$ & $0.02 \pm 0.00$ \\
\hline Nickel & $0.17 \pm 0.017$ & $0.12 \pm 0.02$ & $0.04 \pm 0.00$ & $0.22 \pm 0.03$ & $0.14 \pm 0.03$ \\
\hline Iron & $8.80 \pm 0.31$ & $8.48 \pm 0.59$ & $9.72 \pm 0.22$ & $10.75 \pm 0.13$ & $10.20 \pm 0.41$ \\
\hline Sodium & $8.45 \pm 0.34$ & $10.11 \pm 0.23$ & $10.49 \pm 0.13$ & $9.82 \pm 0.23$ & $9.88 \pm 0.28$ \\
\hline Potassium & $8.50 \pm 0.28$ & $7.93 \pm 0.15$ & $8.51 \pm 0.10$ & $8.28 \pm 0.16$ & $7.07 \pm 0.22$ \\
\hline Calcium & $18.54 \pm 2.54$ & $4.62 \pm 1.11$ & $7.58 \pm 1.03$ & $1.04 \pm 0.25$ & $7.99 \pm 0.35$ \\
\hline Total alkalinity & $693.45 \pm 158.5$ & $83.43 \pm 2.81$ & $116.05 \pm 1.52$ & $60.85 \pm 5.92$ & $67.39 \pm 2.11$ \\
\hline BOD & $11.03 \pm 0.87$ & $17.51 \pm 0.86$ & $13.73 \pm 0.41$ & $12.78 \pm 0.78$ & $12.57 \pm 0.64$ \\
\hline COD & $69.82 \pm 1.95$ & $72.32 \pm 0.48$ & $73.77 \pm 0.84$ & $63.27 \pm 0.51$ & $65.60 \pm 2.57$ \\
\hline Total hardness & $328.05 \pm 21.09$ & $573.03 \pm 97.51$ & $1318.65 \pm 95.80$ & $155.07 \pm 8.22$ & $395.16 \pm 24.34$ \\
\hline Chloride & $432.47 \pm 56.97$ & $145.18 \pm 7.15$ & $114.79 \pm 5.65$ & $110.49 \pm 1.91$ & $114.76 \pm 3.65$ \\
\hline Phosphate & $120.08 \pm 5.82$ & $108.34 \pm 5.25$ & $150.91 \pm 4.95$ & $116.71 \pm 2.88$ & $137.99 \pm 5.69$ \\
\hline ulphate & $59.69 \pm 2.24$ & $62.98 \pm 3.76$ & $69.82 \pm 3.93$ & $79.92 \pm 2.05$ & $43.31 \pm 1.78$ \\
\hline Sulphide & $39.94 \pm 1.76$ & $39.43 \pm 3.37$ & $40.05 \pm 1.17$ & $45.08 \pm 2.02$ & $37.60 \pm 3.71$ \\
\hline Nitrate & $43.34 \pm 3.15$ & $60.84 \pm 4.22$ & $93.97 \pm 1.52$ & $95.01 \pm 2.69$ & $83.75 \pm 1.76$ \\
\hline Total coliform & $50.71 \pm 9.86$ & $19.45 \pm 2.18$ & $19.14 \pm 1.40$ & $27.77 \pm 3.38$ & $4.19 \pm 0.18$ \\
\hline Dissolved $\mathrm{O}_{2}$ & $13.62 \pm 0.49$ & $11.39 \pm 0.43$ & $11.82 \pm 0.52$ & $9.49 \pm 0.33$ & $11.07 \pm 0.95$ \\
\hline Magnesium & $10.87 \pm 1.34$ & $8.66 \pm 0.80$ & $7.69 \pm 0.36$ & $7.25 \pm 0.42$ & $14.44 \pm 0.78$ \\
\hline Chromium & $0.01 \pm 0.002$ & $0.02 \pm 0.01$ & $0.01 \pm 0.00$ & $0.02 \pm 0.00$ & $0.03 \pm 0.00$ \\
\hline Manganese & $1.56 \pm 0.26$ & $1.79 \pm 0.25$ & $0.67 \pm 0.08$ & $3.91 \pm 0.37$ & $1.01 \pm 0.15$ \\
\hline Cadmium & $0.01 \pm 0.002$ & $0.00 \pm 0.00$ & $0.01 \pm 0.00$ & $0.01 \pm 0.00$ & $0.01 \pm 0.00$ \\
\hline
\end{tabular}


Table 3. Comparison of characteristics of untreated leachate in Ogbomosoland with FEPA standard.

\begin{tabular}{|c|c|c|c|c|c|c|c|c|c|c|c|}
\hline \multirow{2}{*}{$\begin{array}{l}\text { Measured } \\
\text { Parameter }\end{array}$} & \multirow{2}{*}{$\begin{array}{c}\text { FEPA } \\
\text { standard }\end{array}$} & \multicolumn{2}{|c|}{ Ogbomoso North } & \multicolumn{2}{|c|}{ Ogbomoso South } & \multicolumn{2}{|c|}{ Oriire } & \multicolumn{2}{|c|}{ Ogo Oluwa } & \multicolumn{2}{|c|}{ Suurulere } \\
\hline & & $\begin{array}{l}\text { \% below } \\
\text { standard }\end{array}$ & $\begin{array}{l}\text { \% above } \\
\text { standard }\end{array}$ & $\begin{array}{l}\text { \% below } \\
\text { standard }\end{array}$ & $\begin{array}{l}\text { \% above } \\
\text { standard }\end{array}$ & $\begin{array}{l}\text { \% below } \\
\text { standard }\end{array}$ & $\begin{array}{l}\text { \% above } \\
\text { standard }\end{array}$ & $\begin{array}{l}\text { \% below } \\
\text { standard }\end{array}$ & $\begin{array}{l}\% \text { above } \\
\text { standard }\end{array}$ & $\begin{array}{l}\text { \% below } \\
\text { standard }\end{array}$ & $\begin{array}{l}\text { \% above } \\
\text { standard }\end{array}$ \\
\hline \multicolumn{12}{|l|}{ Appearance } \\
\hline \multicolumn{12}{|l|}{ Colour } \\
\hline \multicolumn{12}{|l|}{ Odour } \\
\hline Temperature & 35.00 & 25.11 & - & 17.40 & - & 26.69 & - & 26.4. & - & 26.97 & - \\
\hline Conductivity & 125.00 & 30.31 & - & 9.21 & - & 5.65 & - & 53.28 & - & 55040 & - \\
\hline Turbidity pH & 5.00 & - & 166.00 & - & 2.00 & - & 2.00 & - & 9.00 & 1.00 & - \\
\hline Zinc & $6.00-9.00$ & - & - & ND & ND & ND & ND & ND & ND & ND & ND \\
\hline Copper & 5.00 & - & 521.80 & - & 155.60 & - & 37.20 & - & 104.60 & - & 22.80 \\
\hline Lead & 0.05 & - . & 11.20 & - . & 1000.00 & 100.00 & - & 0 & 0 & - & 14.2 \\
\hline Nickel & 0.01 & - & - & - & 100.00 & 0.00 & 0 & - & 300.00 & - & 100.00 \\
\hline Iron & 0.05 & - & 240.00 & - & 140.00 & 20.00 & - & - & 340.00 & - & 180.00 \\
\hline Sodium & 0.50 & - & 1660 & - & 1596.00 & - & 1844.00 & - & 2050.00 & - & - \\
\hline Potassium & 100 & 91.55 & - & 89.89 & - & 89.51 & - & 90.18 & - & 90.12 & 1940.00 \\
\hline Calcium & 50.00 & 83.00 & - & 84.14 & - & 82.98 & - & 83.44 & - & 85.86 & - \\
\hline \multirow[t]{2}{*}{ Total alkalinity } & 4.50 & - & 312.00 & - & 2.67 & - & 68.44 & 76.89 & - & - & - \\
\hline & 75.00 & - & 824.00 & - & 11.24 & - & 54.73 & 18.87 & 1 & 10.15 & 77.56 \\
\hline BOD & 30.00 & 63.23 & - & 41.63 & - & 54.23 & - & 57.40 & - & 58.10 & - \\
\hline COD & 75.00 & 6.91 & - & 3.57 & - & 1.64 & - & 15.64 & - & 12.53 & - \\
\hline Total solids & 500.00 & 77.27 & - & 79.30 & - & 69.34 & - & 83.86 & - & 86.92 & - \\
\hline Total hardness & 200.00 & - & 64.03 & - & 186.52 & - & 559.33 & 22.47 & - & - & - \\
\hline Chloride & 100.00 & - & 332.47 & - & 45.18 & - & 14.79 & - & 10.49 & - & 97.58 \\
\hline Phosphate & 50.00 & - & 140.16 & - & 116.68 & - & 201.82 & - & 133.42 & & 14.76 \\
\hline Sulphate & 100.00 & 40.31 & - & 37.02 & - & 30.18 & - & 20.18 & - & 56.69 & 175.98 \\
\hline Sulphide & 100.00 & 60.06 & - & 39.43 & - & 59.95 & - & 54.92 & - & 62.40 & - \\
\hline Nitrate & 20.00 & - & 116.76 & - & 204.20 & - & 369.85 & - & -375.05 & - & - \\
\hline Total coliform & 400.00 & 87.32 & - & 95.13 & - & 95.22 & - & 93.06 & - & 98.95 & 318.75 \\
\hline Dissolved $\mathrm{O}_{2}$ & 5.00 & - & 172.40 & - & 127.80 & - & 136.40 & - & 89.80 & - & -121.40 \\
\hline Magnesium & 125.00 & 91.30 & - & 93.07 & - & 93.85 & - & 94.20 & - & 88.45 & - \\
\hline Chromium & 0.20 & 93.00 & - & 90.00 & - & 95.00 & - & 90.00 & - & - & 75.00 \\
\hline Manganese & 0.05 & - & 3020.00 & - & 3480.00 & - & 1240.00 & - & 7720.00 & - & 1920.00 \\
\hline Cadmium & 0.01 & 0 & 0 & 100.00 & - & 0 & 0 & 0 & 0 & 0 & 0 \\
\hline
\end{tabular}

directly linked to high pollution values from heavy metals like copper, lead, zinc, and nickel. Excess nitrate value could particularly be related to combustion processes in dumpsites which release nitrogen oxide gas. Cadmium however is moderately present in Ogbomoso North LGA and its concentration is about the same with the recommended standard. The result of some leachate characteristics here is in agreement with those quoted by [25] in a study on Lagos dumpsites. The Ogbomoso North LGA and Lagos mean leachate values respectively for COD are 69.8 and $80.1 \mathrm{mg} / \mathrm{l}$, chloride; 432.5 and $355.3 \mathrm{mg} / \mathrm{l}$, iron; 8.8 and $14.8 \mathrm{mg} / \mathrm{l}$. The BOD/COD ratio in Ogbomoso North LGA stood at 0.2 which is equally in congruent with the reported value of 0.3 by [25] in the Lagos dumpsite.

From Tables 2 and 3, the data indicate that in Ogbomoso South LGA some parameters also have values well above the FEPA standard. In this city LGA, industrial activities like steel processing, waste combustion, immersion and freezing of food products, electrical works, roofing and plumbing works, paper production, painting works, bleaching are all accountable for higher pollution 
values from heavy metals and chemical constituents recorded. On the other hand, 12 measured characteristics have values below the standard. Perhaps being a study covering aged, stabilized waste, the BOD and COD values were both noticed to be below the given standard. The leachate characteristics in Ogbomoso South LGA have a high level of resemblance with those of Ogbomoso North LG, probably due to their locations within the city. The percentages of some parameters below the standards are also observed to be close in both LGAs. The BOD/COD ratio of leachate here was 0.24 indicating a stabilized leachate in methanogenic stage.

The pattern of pollution levels in Oriire LGA is also as shown in Tables 2 and 3. Among the parameters which constitute heavy contamination in this LGA are zinc, iron, calcium, total alkalinity, phosphate, total hardness, chloride, nitrate, dissolved oxygen and manganese. It is noted from the data that iron, total hardness, phosphate, nitrate and manganese all have extremely high pollution values. This could be as a result of excessive application of fertilizers containing phosphorus and nitrogen salts for agricultural work in this village LGA. It is also noteworthy that values of heavy metals are less probably due to minimal industrial activities in the LGA as compared to those of the LGAs in the city. The discarded tools and implements like cutlasses, hoes, knives, sickles, and the likes might have been responsible for the heavy pollution due to iron, calcium, and manganese. Pesticides made of manganese and other metallic ions could also be the source of these pollution. However, $\mathrm{pH}$, conductivity, turbidity, lead, nickel, sodium, potassium, BOD, COD, total solids, sulphate, sulphite, total coliform, magnesium, chromium, and cadmium values are close to recommended FEPA standard. The leachate here is relatively more stabilized than those of the Ogbomoso South LGA as its BOD/ COD ratio is found to be 0.19 . This may be due to the fact that Oriire is classified as a rural LGA where open dumping of refuse is rampant.

Tables 2 and $\mathbf{3}$ indicate that parameters like temperature, conductivity, $\mathrm{pH}$, potassium, sodium, calcium, total alkalinity, BOD, COD, total solids, total hardness, sulphite, total coliform, magnesium and chromium all have values which are lower than the recommended standard for Ogo Oluwa LGA. However, the values of turbidity, zinc, lead, nickel, iron, total hardness, chloride, phosphate, nitrate, dissolved oxygen and manganese are well pronounced. Copper and cadmium both have values similar to the FEPA standard. The leachate characteristic typically represents an agrarian environment where metals and chemical compound derivable from agricultural activities pollute the ground water. The presence of some metals in excess could be traced to certain agricultural products like cassava, maize and yam which are being processed at Odo Oba town in the LGA. Notable high values of heavy metals like lead, nickel, iron, manganese and zinc could be linked directly to garri processing works prominent at towns in this LGA. The BOD/COD ratio in Ogo-Oluwa LGA leachate is similar to that of Oriire LGA, another rural community; it is averaged 0.20 meaning a methanogenic substance. The leachate of this LGA is considerably hard, this also may be due to agricultural wastes dominating the dumps.

When the leachate parameters in Suurulere local government areas are compared with the FEPA standard, it is observed that pollution is established especially for parameters like zinc, copper, lead, nickel, iron, calcium, total hardness, chloride, phosphate, nitrate, dissolved oxygen and manganese (Tables 2 and 3). Meanwhile, values lower than the FEPA standards are observed for temperature, conductivity, turbidity, sodium, potassium, total alkalinity, BOD, COD, total solids, sulphate, sulphite, total coliform, magnesium and chromium. Cadmium and $\mathrm{pH}$ values are in the same range with the recommended standard. The pollution level in this LGA is explained by automobile workshops at Gambari trailer park and other industrial activities in the area. The lower values of BOD, COD, total coliform and dissolved oxygen are perhaps due to the age factor, and most dumpsites considered are in the methanogenic or stabilized stage. The LGA despite being a rural one has higher pollution levels of chemical compounds than Oriire and Ogo Oluwa perhaps due to more industrial activities taking place here.

\subsection{Comparative Study of Mean Leachate Values}

The overall mean leachate characteristics in Ogbomosoland are presented in Table 4. The average values of all the measured parameters in the 5 LGAs are presented alongside with the Nigerian FEPA standard in Table 5. The temperature ranges from $25.6^{\circ} \mathrm{C}$ and $28.9^{\circ} \mathrm{C}$ with a mean value of $26.4^{\circ} \mathrm{C}$. This falls within the recommended FEPA standard. The conductivity values were generally within the specified standard values of $<125 \mathrm{~g} / \mathrm{cm}$. The leachate samples from the study area were all slightly alkaline with a mean $\mathrm{pH}$ value of 7.9.

Pollution by heavy metals was imminent in some LGAs. For example, zinc causes pollution most in Ogbomoso North LGA with mean values of $31.1 \mathrm{mg} / \mathrm{l}$ as against the $5.0 \mathrm{mg} / \mathrm{l}$ recommended by the standard. The average mean value of zinc in all the LGAs is $13.0 \mathrm{mg} / \mathrm{l}$ thus being almost thrice the recommended value by the FEPA standard. Copper, Nickel, Iron and Manganese all have higher values than maximum limits specified by standards. Values of these heavy metals were observed to be relatively higher in the city than at the surrounding villages. This may be due to industrial activities taking place in the city [26].

Phosphate and nitrate values also indicate heavy pollution 
Table 4. Mean leachate characteristics of Ogbomosoland.

\begin{tabular}{|c|c|c|c|c|c|c|}
\hline Parameter & Ogbomoso North LGA & Ogbomoso South LGA & Oriire LGA & Ogo Oluwa LGA & Suurulere LGA & Overall Average \\
\hline Appearance & & $=\mathrm{CLOUDY}=$ & & & & \\
\hline Colour & & $=$ OBJECTIONABLE= & & & & \\
\hline Odour temperature & 26.21 & $=$ OBJECTIONABLE $=28.91$ & 25.66 & 25.76 & 25.56 & 26.42 \\
\hline Conductivity & 87.11 & 113.49 & 117.94 & 58.40 & 55.75 & 86.54 \\
\hline Turbidity & 13.30 & 5.10 & 5.10 & 5.45 & 4.95 & 6.78 \\
\hline $\mathrm{pH}$ & 8.19 & 7.80 & 7.77 & 7.83 & 7.79 & 7.88 \\
\hline Zinc & 31.09 & 10.78 & 6.86 & 10.23 & 6.14 & 13.02 \\
\hline Copper & 0.61 & 0.55 & 0.00 & 0.05 & 0.76 & 0.39 \\
\hline Lead & 0.01 & 0.02 & 0.01 & 0.04 & 0.02 & 0.02 \\
\hline Nickel & 0.17 & 0.12 & 0.04 & 0.22 & 0.14 & 0.14 \\
\hline Iron & 8.80 & 8.48 & 9.72 & 10.75 & 10.20 & 9.59 \\
\hline Sodium & 8.45 & 10.11 & 10.49 & 9.85 & 9.88 & 9.76 \\
\hline Potassium & 8.50 & 7.93 & 8.51 & 8.28 & 7.07 & 8.06 \\
\hline Calcium & 18.54 & 4.62 & 7.58 & 1.04 & 7.99 & 7.95 \\
\hline Total alkalinity & 693.45 & 83.43 & 116.05 & 60.85 & 67.39 & 204.23 \\
\hline BOD & 11.03 & 17.51 & 13.73 & 12.78 & 12.57 & 13.52 \\
\hline COD & 69.82 & 72.32 & 73.77 & 63.27 & 65.60 & 68.96 \\
\hline BOD/COD ratio & 0.16 & 0.24 & 0.19 & 0.20 & 0.19 & 0.19 \\
\hline Total solids & 113.66 & 103.51 & 153.28 & 80.68 & 65.40 & 103.29 \\
\hline Total hardness & 328.05 & 573.03 & 1318.65 & 155.07 & 395.16 & 553.99 \\
\hline Chloride & 432.47 & 145.18 & 114.79 & 110.49 & 114.76 & 553.99 \\
\hline Phosphate & 120.08 & 108.34 & 150.91 & 116.71 & 137.99 & 126.81 \\
\hline Sulphate & 59.69 & 62.98 & 69.82 & 79.92 & 43.31 & 63.14 \\
\hline Sulphite & 39.94 & 39.43 & 40.05 & 45.08 & 37.60 & 40.42 \\
\hline Nitrate & 43.34 & 60.84 & 93.97 & 95.01 & 83.75 & 75.38 \\
\hline Total coliform & 50.71 & 19.45 & 19.14 & 27.77 & 4.19 & 24.25 \\
\hline Dissolved $\mathrm{O}_{2}$ & 13.62 & 11.39 & 11.82 & 9.49 & 11.07 & 11.48 \\
\hline Magnesium & 10.87 & 8.66 & 7.69 & 7.25 & 14.44 & 9.78 \\
\hline Chromium & 0.01 & 0.02 & 0.01 & 0.02 & 0.03 & 0.02 \\
\hline Manganese & 1.56 & 1.79 & 0.67 & 3.91 & 1.01 & 1.79 \\
\hline Cadmium & 0.01 & 0.00 & 0.01 & 0.01 & 0.01 & 0.01 \\
\hline
\end{tabular}

levels. These are more pronounced in the villages than in the city. This could be traced to the residual values of anions in fertilizers being used for agricultural purposes in these areas. The BOD and COD values observed in the study areas were generally below the recommended standard. The BOD/COD ratio ranged between 0.16 and 0.24 with a mean value of 0.19 indicating stabilized leachates. Likewise the DO values were low compared with those known with strong leachates. These lower range constituents are other pointers to the fact that the leachates of the dumpsites considered in the study area were in their methanogenic stage and were therefore relatively stabilized. Other pollutants recorded in the study area are Calcium, Alkalinity and Hardness. As indicated in the Table 5, these parameters have mean values exceeding the recommended standards. Sodium, Total solids, Sulphate, Sulphide, Total coliform, Magnesium and Cadmium all have mean values either less than or same with the FEPA regulations. As such, they are no threats to leachate pollution in the study area. 
Table 5. Comparison of overall mean leachate values in Ogbomosoland with the FEPA standards.

\begin{tabular}{|c|c|c|}
\hline Measured Parameter & Overall mean & FEPA Standard \\
\hline Appearance & Cloudy & N/A \\
\hline Colour & Objectionable & N/A \\
\hline Odour & Objectionable & N/A \\
\hline Temperature & 26.42 & 35.00 \\
\hline Conductivity & 86.54 & 125.00 \\
\hline Turbidity pH & 6.78 & 5.00 \\
\hline Zinc & 7.88 & $6.00-9.00$ \\
\hline Copper & 13.02 & 5.00 \\
\hline Lead & 0.39 & 0.05 \\
\hline Nickel & 0.02 & 0.01 \\
\hline Iron & 0.14 & 0.05 \\
\hline Sodium & 9.59 & 0.5 \\
\hline Potassium & 9.75 & 100.00 \\
\hline Calcium & 8.06 & 50.00 \\
\hline Total & 7.95 & 774.50 \\
\hline Alkalinity & 204.23 & 75.00 \\
\hline BOD & 13.52 & 30.00 \\
\hline COD & 68.96 & 75.00 \\
\hline BOD/COD ratio & 0.19 & 0.40 \\
\hline Total solids & 103.29 & 500.00 \\
\hline Total hardness & 553.99 & 200.00 \\
\hline Chloride & 183.54 & 100.00 \\
\hline Phosphate & 126.81 & 50.00 \\
\hline Sulphate & 63.14 & 100.00 \\
\hline Sulphide & 40.42 & 100.00 \\
\hline Nitrate total & 75.38 & 20.00 \\
\hline Coliform & 24.25 & 400.00 \\
\hline Dissolved $\mathrm{O}_{2}$ & 11.48 & 5.00 \\
\hline Magnesium & 9.78 & 125.00 \\
\hline Chromium & 0.02 & 0.20 \\
\hline Manganese & 1.79 & 0.05 \\
\hline Cadmium & 0.01 & 0.01 \\
\hline
\end{tabular}

\section{Conclusion}

The mean leachate characteristics of the study area, especially in the high income (urban) LGAs, by FEPA standards were found to be sources of pollution when compared with the environmental regulation standards. It is therefore recommended that leachates emanating from these dumpsites be prevented from contaminating the underground water resources of the five (5) LGAs of Ogbomosoland. Liner materials are hereby suggested for leachate management in the study area.

\section{REFERENCES}

[1] O. Hester and C. Harrison, “Groundwater Pollution,” 2005. http://www.groundwaterpollution.com

[2] C. K. Calvert, "Contamination of Groundwater by Impounded Garbage Waste,” Journal of American Works Association, Vol. 24, No. 2, 1932, p. 266.

[3] J. D. Englehardt and Y. Deng, “Options for Managing Municipal Landfill Leachate: Year One Development of Iron-Mediated Treatment Processes,” 2007. www.floridacentre.org

[4] USEPA, "Manual: Groundwater and Leachate Treatment Systems," Centre for Environmental Research Informationk, Vol. 2, No. 9, 1995, pp. 1-64.

[5] T. Viraraghavan and K. S. Singh, "Anaerobic Biotechnology for Leachate Treatment: Areview," Proceedings of the Air and Waste Management Associatio's Annual Meeting and Exhibition, 12-15 September 1997, pp. 112-123.

[6] E. S. K. Chian and F. B. DeWalle, "Leachate Matters," Environmental Science and Technology, Vol. 11, No. 2, 1977, p. 150.

[7] H. C. Robinson and P. J. Maris, "Leachate from Domestic Waste Generation, Composition and Treatment: A Review,” Water Research Centre, Technical Report TR 108, 1979, p. 170.

[8] R. D. Cameron and F. A. Koch, "Toxicity of Landfill Leachates," Journal of the World Pollution Control Federation, Vol. 52, 1980, pp. 760-769.

[9] J. B. Brice, F. B. DeWalle, E. S. K. Chian and M. Asce, "The Chemical Composition of Leachates Derived from Various Fractions of Domestic Refuse,” AERE. R-10938, Harwell, 1984.

[10] H. S. Ehrig and R. Stegmann, "Leachate Production and Quality Results of Landfill Processes and Operation,” Proceedings of 2nd International Landfill Symposium, Sardinia, 1989, pp. 223-229.

[11] G. J. Farquhar, "Leachate Production and Characterization,” Canadian Journal of Civil Engineering, Vol. 16, 1989, pp. 317-325. doi:10.1139/189-057

[12] S. C. Alker, P. Baccinq and J. B. Brice, "The Composition of Leachate from Waste Disposal Sites," Green, Bolton, 1993, pp. 121-135.

[13] T. H. Christensen, R. Cossu and R. Stegmann, "Organic Carbons in Landfill Leachates,” Proceedings Sardinia 99, 7th International Waste Management and Landfill Symposium, Vol. 4, 1999, pp. 117-124.

[14] H. D. Robinson, "Development of Methanogenic Conditions within Landfills,” Proceedings of 2nd International Landfill Symposium, Sardina, October 1989, pp. 225-240.

[15] EAW, “A Working Environment for Wales Report,” Environment Agency Wales, Cardiff, 1999, pp. 35-41.

[16] A. Y. Sangodoyin, "Groundwater and Surface Water Pollution by Open Dump in Ibadan, Nigeria,” Discovery and Innovation, Vol. 2, No. 1, 1991, pp. 37-43.

[17] O. A. Agbede, "Pollution Levels in Some Existing Wells in Ibadan City,” Technical Paper Presented at the Workshop on Water Supply and Environmental Sanitation, University of Ibadan, Ibadan, 1991.

[18] BS 1377, "Methods of Test for Soils for Civil Engineering Purposes,” British Standards Institution, London, 1975, 
pp. 1-28.

[19] SSSA, "Methods of Soil Analysis," Soil Science Society of America, 2nd Edition, 1982, pp. 209-224.

[20] M. H. Fulakar and J. M. Dave, "Release and Behaviour of Chromium, Manganaese, Nickel and Lead in a Fly-Ash, Soil, Water Environment," Journal of Environmental Studies, No. 30, 1991, pp. 281-296.

[21] APHA, "Standard Methods for the Examination of Water and Wastewater," 15th Edition, American Public Health Association, New York, 1998.

[22] FEPA, "National Interim Guidelines and Standards for Industrial Effluents and Water Quality Tests,” Federal En- vironmental Protection Agency, 1991, pp. 32-59.

[23] B. Welz, “Atomic Absorption Spectrophotometry,” 2nd Edition, Pengamon Press, Oxford, 1985, pp. 164-171.

[24] C. M. A. Ademoroti, "Standard Methods for Water and Effluents Analyses,” IUPAC System, S.I. Units, Foludex Press, Ibadan, 1996.

[25] A. Ikem, "Environmental Impact of Two Waste Dumpsites in Ibadan and Lagos on Groundwater Quality,” Ph.D. Thesis, University of Ibadan, Ibadan, 1998, pp. 30-40.

[26] S. O. Ojoawo, "Management of Leachate Pollution from Dumpsites in Ogbomosoland, Nigeria,” Ph.D. Thesis, University of Ibadan, Ibadan, 2009, pp. 130-131. 